\title{
Pancreatic extragastrointestinal stromal tumor invading the duodenum
}


Cebrail Akyüz¹ (1), Sibel Kayahan² (1)

\section{ABSTRACT}

ORCID IDs of the authors: S.Y. 0000-0001-7631-0935; E.P. $0000-0002-9463-9846 ;$ M.D. 0000-0002-0276-0543; 0.U. 0000-0001-7586-9075; N.F.Y. 0000-0002-9751-2912; K.D.P. $0000-0002-8887-3505$; C.A. $0000-0003-0917-9345$; S.K. 0000-0001-5124-3916

Cite this paper as: Yol S, Polat E, Duman $\mathrm{M}$, Uzun 0, Yaşar NF, Peker KD, Akyüz C, Kayahan S. Pancreatic extragastrointestinal stromal tumor invading the duodenum. Turk J Surg 2018 34 (3): 231-233

'Department of Gastrointestinal Surgery, Kartal Koşuyolu Yüksek İhtisas Training and Research Hospital, İstanbul, Turkey

2Department of Pathology, Kartal Training and Research Hospital, İstanbul, Turkey

This study was presented at the $18^{\text {th }}$ National Congress of Surgery $\& 13^{\text {th }}$ Congress of Surgical Nursing, 23-27 May 2012, İzmir, Turkey.

\section{Corresponding Author} Erdal Polat

e-mail: erdal066@yahoo.com

Received: 12.03.2014

Accepted: 19.08.2015

Available Online Date: 03.01.2018

CCopyright 2018

by Turkish Surgical Association

Available online at

www.turkjsurg.com
Extragastrointestinal stromal tumors that arise in the pancreas are extremely rare and managing them can be difficult, particularly if located in the head of pancreas. This case report aims to contribute to the existing data in the literature regarding extragastrointestinal stromal tumors with rare and unusual locations. We present a 56 -year-old man who presented with recurrent mild right upper quadrant abdominal pain. Abdominal computed tomography and magnetic resonance imaging revealed a mass lesion with a diameter of $10 \mathrm{~cm}$ localized in the head of pancreas. Pancreaticoduodenectomy with complete tumor excision was performed. He was discharged on the postoperative day 14 . Only 15 extragastrointestinal stromal tumors cases have been reported. Of these 15 cases, tumors were located in the head of pancreas in six cases. Here we report the seventh case of pancreatic extragastrointestinal stromal tumor arising in the head of pancreas and also the largest of these seven tumors. Keywords: Pancreas, extragastrointestinal tumor, stromal tumor

\section{INTRODUCTION}

Gastrointestinal stromal tumors (GISTs) are low-grade malignancies of mesenchymal origin in the gastrointestinal tract, and these tumors arise from the intestinal cells of Cajal (1-3). These tumors may originate from any location in the entire gastrointestinal tract, and the most susceptible sites are the stomach (40\%-60\%), small intestine (30\%-40\%), colon and rectum (5\%), and esophagus $(5 \%)$, whereas only $3 \%-5 \%$ of GISTs occur in the duodenum (4-6). There are also sporadic reports of GISTs that arise from the peritoneum, omentum, mesentery, and retroperitoneum $(2,3,7)$. GISTs that originate from the soft tissues of the abdomen and retroperitoneum are called extragastrointestinal stromal tumors (EGISTs). EGISTs that arise from the pancreas are extremely rare, and only 15 cases have been previously reported (7-9). Here we report a case of a large pancreatic EGIST that invaded the duodenum.

\section{CASE PRESENTATION}

A 56-year-old man presented with recurrent mild right upper quadrant abdominal pain that radiated to the back of his torso. The patient had a history of melena, which required blood transfusion. After his admission owing to melena, a series of endoscopic and radiologic investigations was conducted, but it failed to reveal the source of bleeding; however, only hyperemia of the antrum and hiatal insufficiency were detected. There was no remarkable finding in his medical history and no weight loss. Abdominal examination revealed right upper quadrant tenderness. Laboratory test findings showed that the peripheral blood cell count and blood chemistry were within normal limits, except anemia (hemoglobin, $9 \mathrm{~g} / \mathrm{dl}$; reference range, 13-17 g/dL). Tumor markers were negative for CA 19-9, CA 125, and CEA. Abdominal computed tomography $(\mathrm{CT})$ revealed an $11-\mathrm{cm}$-diameter mass lesion that originated from the head of pancreas and extended to the right paranephritic fat tissue. The fat plane between the duodenum and the pancreas was obliterated by the tumor. MRI (Figure 1,2) also revealed a 10.5-cm-diameter mass lesion localized at the head of pancreas; however, there was no dilatation or invasion of the common bile duct.

Pancreaticoduodenectomy (Whipple's procedure) was performed as the treatment of choice. The tumor was palpated as a hard mass in the head of pancreas. The tumor was $15 \mathrm{~cm}$ in diameter and extended from the duodenum through to the retroperitoneum and inferior cecal region. Macroscopically, there were no metastases in the peritoneum or liver. The postoperative course was uneventful, and the patient was discharged on the postoperative day 14. The histopathological examination the specimen confirmed EGIST, with predominant spindle cells and mitotic figures of fewer than three per 50 highpower fields. Wide necrotic areas in the tumor were also noted. The surgical margins were negative, and no metastasis was noted in the six regional lymph nodes, which were excised. Immunohistochemistry revealed that the tumor cells were positive for CD117, CD34, and vimentin (Figure 3-6) and negative for S100 and desmin. Imatinib (400 mg daily) administration was initiated in the third postoperative week as adjuvant therapy.

Written informed consent is obtained from the patient for the publication of this case report and accompanying images. 
Yol et al.

Pancreatic extragastrointestinal stromal tumor

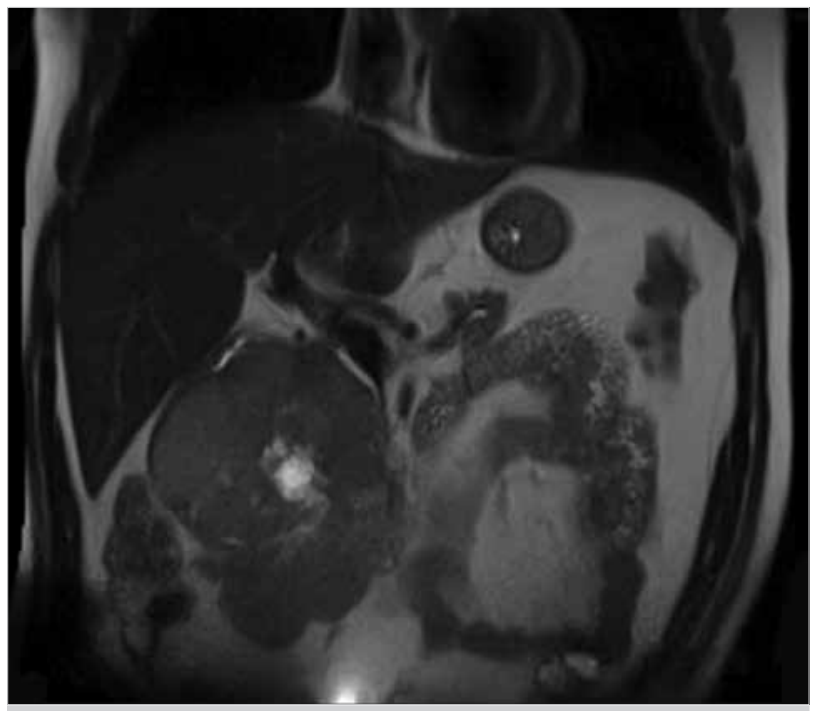

Figure 1. MRI demonstrating the pancreatic mass (coronal view)

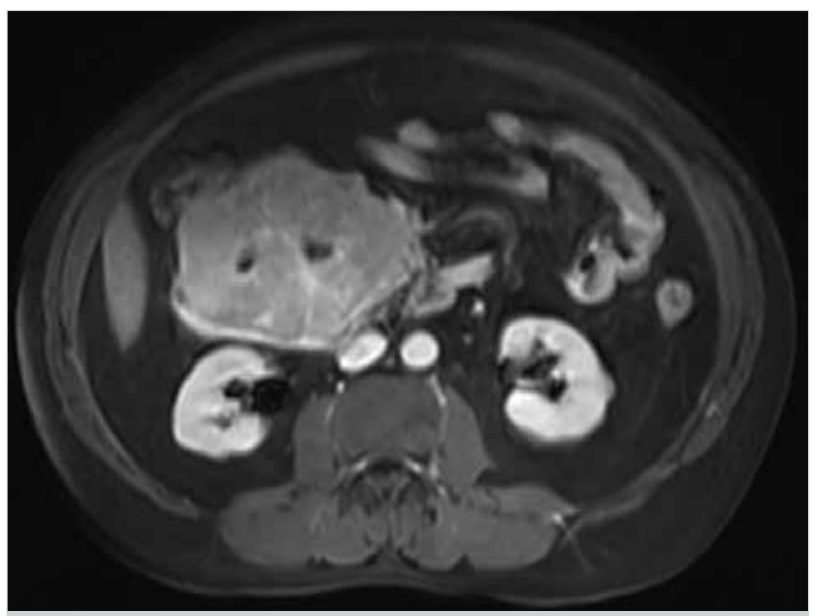

Figure 2. MRI demonstrating the pancreatic mass (axial view)

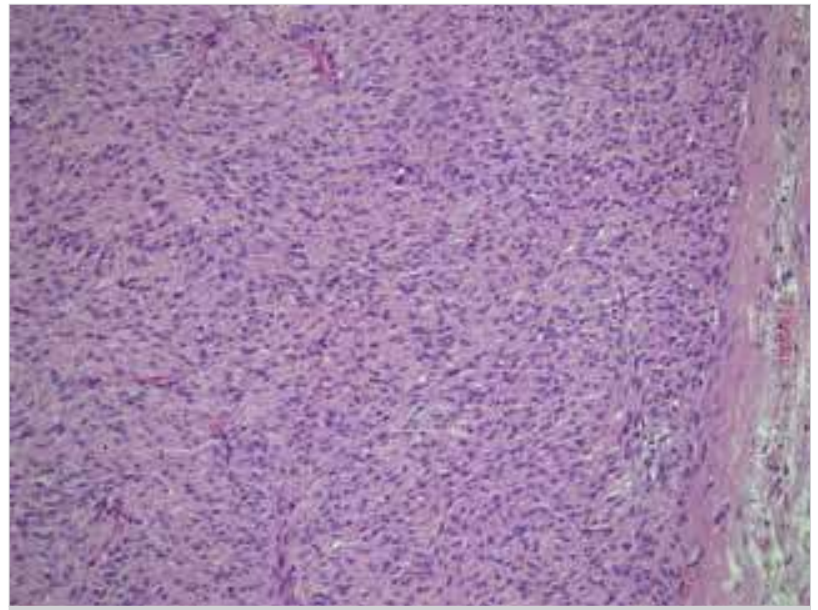

Figure 3. Tumor cells (H\&E, 10X)

\section{DISCUSSION}

Gastrointestinal stromal tumors are low-grade malignant mesenchymal tumors and the most common non-epithelial tumor of the gastrointestinal tract, which is believed to originate from the interstitial cells of Cajal. Cajal cells are located in the muscle layer of the gastrointestinal tract as the pacemaker cells of the gastrointestinal tract and commonly express c-kit proteins (CD117), myeloid

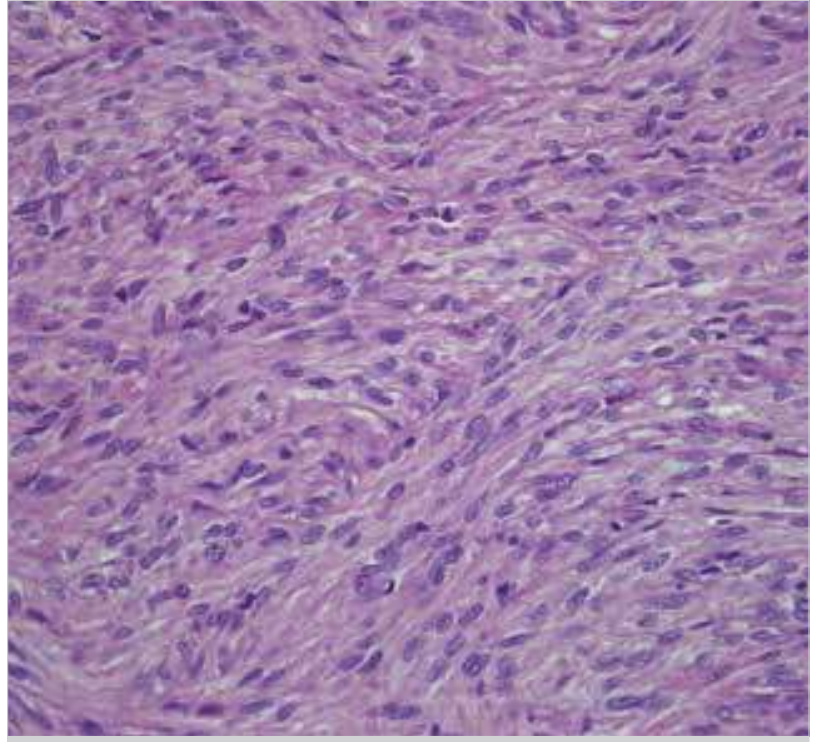

Figure 4. Tumor cells (H\&E, 40X)

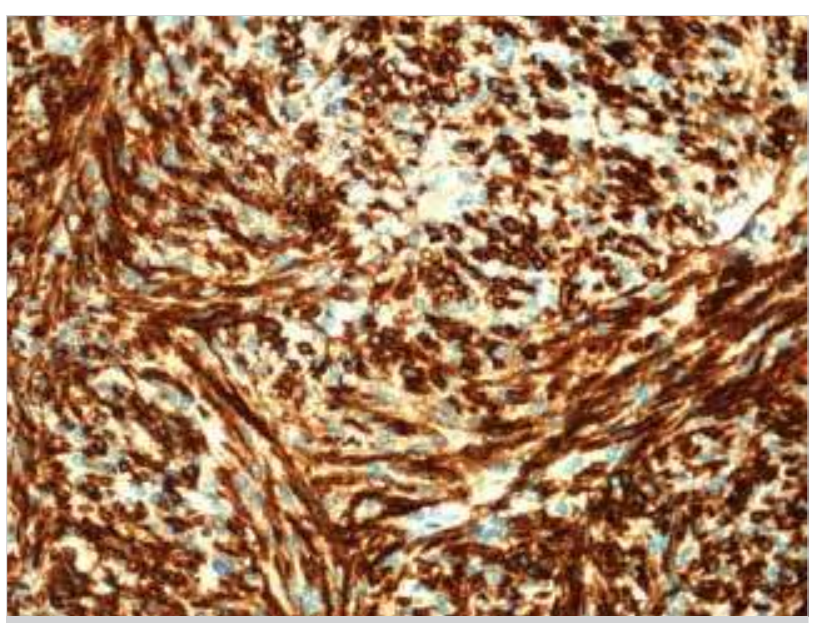

Figure 5. Tumor cells (CD34, 40x)

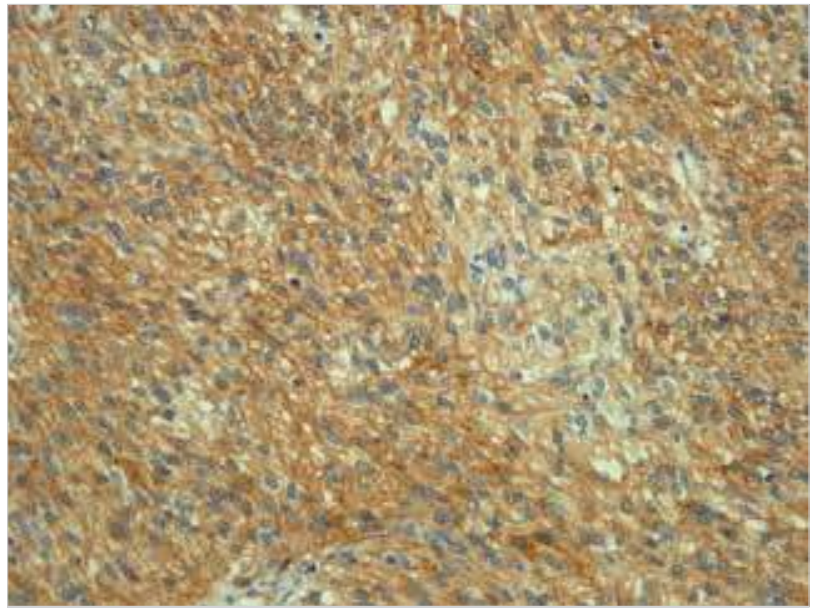

Figure 6. Tumor cells (CD117, 40x)

the CD117 antigen, which is a receptor tyrosine kinase protein that is considered to be the defining characteristic. Approximately $70 \%$ of all GISTs are positive for the CD34 protein, which is a hematopoietic progenitor cell antigen, whereas $20 \%-30 \%$ are positive for SMA and $10 \%$ are positive for the S-100 protein. Approximately $40 \%-60 \%$ of GISTs occur in the stomach, whereas $30 \%-40 \%$ occur in the small intestine, $10 \%$ in other parts of the gastrointestinal tract, and $5 \%$ elsewhere in the abdominal cavity $(3,5,8-14)$. GISTs 
are infrequent neoplasms. The overall incidence of GISTs has been estimated to be $10-20$ cases per million per year, and 300-4000 new cases are reported each year in the United States. The mean age of the patients was 53 years (range, 40-80 years), and only $5 \%$ are aged $<30$ years $(1,3,13)$. GISTs that arise from outside the bowel wall are termed as EGISTs. Pancreatic EGISTs are reported to be very rare, and only 15 cases have been reported. In this study, we present an extremely rare case of a primary pancreatic EGIST.

Preoperative diagnosis of GIST and EGIST is difficult owing to nonspecific signs and symptoms. Abdominal pain, palpable mass, and bleeding are the most common presentations. Small tumors are usually found incidentally during operation, endoscopy, CT, or MRI, which are conducted to investigate other conditions. GISTs and EGISTs are usually diagnosed using CT, MRI, gastrointestinal endoscopy, and barium study. However, these modalities may not always be helpful in specifying the origin of the mass, particularly that of $\operatorname{EGISTs}(5,6,12,13)$.

Pancreatic GISTs are very rare mass lesions, with clinical symptoms such as abdominal pain, early satiety, bleeding, ileus, anemia, and flatulence. EGISTs are often asymptomatic compared with GISTs, and this clinical difference is explained by their locations, size of the tumors, and lack of mucosal involvement. EGISTs tend to grow larger than GISTs before resulting in any symptoms, and their histological features are similar to other GISTs. EGISTs that arise in the head of pancreas are extremely rare, and to date, only 6 cases have been reported in the literature. $(3-6,8,9,11$, $12,14,15)$. Here we report the seventh case of pancreatic EGIST that arose in the head of pancreas and also the largest of these seven tumors. In our case, preoperative imaging studies showed that the mass lesion originated from the head of pancreas, and gastroduodenoscopy showed that the duodenum mucosa was normal. Therefore, this tumor was considered to be a primary pancreatic head tumor with an exophytic growing pattern $(5,6$, 10). The most important prognostic factors for GISTs are the tumor size and mitotic count. Additional factors such as histological variant, mutation type, and anatomic location have been associated with varying prognoses. Optimal surgical treatment of GISTs entails complete tumor removal with clear surgical margins and avoidance of tumor rupture and in some cases, necessitating the resection of adjacent organs. Local and regional lymph node involvement is infrequent in GISTs; therefore, systematic lymph node dissection is not considered necessary. Imatinib mesylate is used in the management of GISTs as adjuvant therapy and in patients with recurrent disease (1, 3-5, 11, 12-17). Our patient had adjuvant treatment with imatinib initiated in the third postoperative week because the patient was evaluated in the high-risk group with the tumor diameter of $>10 \mathrm{~cm}$.

\section{CONCLUSION}

There are very few reports regarding EGISTs that arise from the pancreas. The tenor in our case was considered to arise from the head of pancreas, and Whipple's procedure was performed for its treatment. This report will contribute to the existing data in the literature regarding EGISTs in rare and unusual locations.

Informed Consent: Written informed consent was obtained from patient who participated in this study.

Peer-review: Externally peer-reviewed.

Author Contributions: Concept - S.Y., E.P., M.D.; Design - O.U., N.F.Y., K.D.P., CA; Supervision - S.Y., E.P., M.D.; Resource - O.U., N.F.Y., K.D.P., CA, S.K.; Materials - O.U., N.F.Y., K.D.P., C.A., S.K.; Data Collection and/or Pro- cessing - E.P., M.D., N.F.Y.; Analysis and/or Interpretation - S.Y., E.P., M.D., N.F.Y.; Literature Search - O.U., N.F.Y., K.D.P., C.A., S.K.; Writing Manuscript - E.P., M.D., O.U., N.F.Y.; Critical Reviews - S.Y., E.P., M.D.

Conflict of Interest: The authors have no conflicts of interest to declare.

Financial Disclosure: The authors declared that this study has received no financial support.

\section{REFERENCES}

1. Rubin JL, Sanon M, Taylor DCA, Coombs J, Bollu V, Sirulnik L. Epidemiology, survival, and costs of localized gastrointestinal stromal tumors. Int J Gen Med 2011; 4: 121-130.

2. Fülöp E, Marcu S, Borda A, Moldavan C, Fülöp EF, Loghin A, et al. Histopathological and immunohistochemical features of gastrointestinal stromal tumors. Rom J Morphol Embryol 2011; 52: 555-562.

3. Machado NO, Chopra PJ, Al-Haddabi iH, Al-Qadhi H. Large duodenal gastrointestinal stromal tumor presenting with acute bleeding managed by a Whipple resection. A review of surgical options and the prognostic indicators of outcome. J Pancreas 2011; 12: 194-199.

4. Ghıdırım GH, Mıshın I, Gagauz I, Vozıan M, Cernı A, Cernat M. Duodenal gastrointestinal stromal tumor. Rom J Morphol Embriyol 2011; 52: 1121-1125.

5. Morcos B, Al-Ahmad F. A large gastrointestinal stromal tumor of the duodenum: a case report. J Med Case Rep 2011; 5; 457. [CrossRef]

6. Uchida H, Sasaki A, Iwaki K, Tominaga M, Yada K, Iwashita Y, et al. An extramural gastrointestinal stromal tumor of the duodenum mimicking a pancreatic head tumor. J Hepatobiliary Pancreat Surg 2005; 12: 234-237. [CrossRef]

7. Padhi S, Kongara R, Uppin SG, Uppin MS, Prayaga AK, Challa S, et al. Extragastrointestinal stromal tumor arising in the pancreas: a case report with a review of the literature. J Pancreas 2010; 11: 244-248.

8. Rao RN, Vij M, Singla N, Kumar A. Malignant pancreatic extra gastrointestinal stromal tumor diagnosed by ultrasound guided fine needle aspiration cytology. A case report with a review of the literature. J Pancreas 2011; 12: 283-286.

9. Serin KR, Keskin M, Güllüoğlu M, Emre A. An atypically localized gastrointestinal stromal tumor: a case report of pancreas gastrointestinal stromal tumor. Ulusal Cer Derg 2013; 29: 42-44.

10. Ohtake S, Kobatashi N, Kato S, Kubota K, Endo I, Inayama Y, et al. Duodenal gastrointestinal stromal tumor resembling a pancreatic neuroendocrine tumor in a patient with neurofibromatosis type I (von Reclinghausen's disease): a case report. J Med Case Rep 2010; 4: 302. [CrossRef]

11. Frampton $A E$, Bong JJ, Kyriakides $C$, Cohen P, Jiao LR. En bloc resection of the pancreatic head and the second part of duodenum for a duodenal gastrointestinal stromal tumor: a multimedia report. J Pancreas 2010; 11: 396-400.

12. Patil $\mathrm{S}$, Jain $\mathrm{S}$, Kaza RCM, Chamberlain RS. Giant gastrointestinal stromal tumor presenting as a palpable abdominal mass: an unusual presentation. ISRN Surgery 2011; 2011: 894829. [CrossRef]

13. Cecka F, Jon B, Ferko A, Subrt Z, Nikolov DH, Tycova V. Long term survival of a patient after resection of a gastrointestinal stromal tumor arising from the pancreas. Hepatobiliary Pancreat Dis Int 2011; 10: 330-332. [CrossRef]

14. Vij M, Agrawal V, Pandey R. Malignant extra gastrointestinal stromal tumor of the pancreas. A case report and review of literature. J Pancreas 2011; 12: 200-204.

15. Kim HH, Koh YS, Park EK, Seoung JS, Hur YH, Kim JC, et al. Primary extragastrointestinal stromal tumor arising in the pancreas: report of case. Surg Today 2012; 42: 386-390. [CrossRef]

16. Casali PG, Blay JY. Gastrointestinal stromal tumours: ESMO clinical practice guidelines for diagnosis, treatment and follow up. Annals of Oncology 2010; 21: 98-102. [CrossRef]

17. Chung JC, Kim HC, Chu CW. Segmental duodenectomy with duodenojejunostomy of gastrointestinal stromal tumor involving the duodenum. J Korean Surg Soc 2011; 80: 12-16.[CrossRef] 